EXPERIMENTAL BIOMEDICAL RESEARCH

http://www.experimentalbiomedicalresearch.com

Original Article

\title{
Unexpected risk of gynecological malignant and premalignant disease in women undergoing hysterectomy for pelvic organ prolapse
}

\author{
Mustafa Ayhan Ekici ${ }^{1}$ - Ali Can Onal ${ }^{2}$ \\ ${ }^{I}$ Department of Gynecology and Obstetrics, Bolu Abant Izzet Baysal University, Faculty of Medicine, Bolu, Turkey \\ ${ }^{2}$ Department of Pathology, Bolu Abant Izzet Baysal University, Training and Research Hospital, Bolu, Turkey
}

\section{ABSTRACT}

Aim: To investigate the incidence of unexpected malignant and premalignant gynecological pathological findings among women who underwent hysterectomy due to pelvic organ prolapse (POP).

Methods: In this retrospective study, the medical reports of women who underwent hysterectomy for POP between 2007 and 2019 were investigated to reveal unexpected malignant and premalignant lesions. The possible relationship between pathological results and other variables was evaluated statistically.

Results: The hysterectomy was performed by abdominal (160, 30.53\%), laparoscopic (62\%, 11.83\%) and vaginal approaches $(302,57.63 \%)$ in 524 patients with POP indication. Thirty five patients $(6.67 \%)$ had unexpected premalignant or malignant pathological findings found on hysterectomy specimens. Simple hyperplasia was found in 18 patients $(3.44 \%)$, complex hyperplasia in two patients $(0.38 \%)$; CIN-1 (LSIL) low grade cervical intraepithelial dysplasia in nine patients (1.7\%), CIN-II, moderate dysplasia in two patients $(0.38 \%)$; CIN-III, severe dysplasia in one patient $(0.19 \%)$; vaginal carcinoma in two patients $(0.38 \%)$ and endometrial carcinoma in one patient $(0.19 \%)$. In the vaginal hysterectomy group, the incidence of unsuspected gynecological malignancy was founded at the rate of $0.57 \%(3 / 524)$ and the percentage of the group was significantly higher than laparotomic and laparoscopic hysterectomy groups. Statistically significant difference was not found between the groups with respect to unexpected uterine malignancy.

Conclusion: Women without abnormal vaginal bleeding do not have high risk of premalignant or malignant pathological reporting after uterovaginal prolapse surgery, however it should not be neglected.

Keywords: Pelvic organ prolapse, uterovaginal prolapse, hysterectomy, malignancy.

(C) 2020 experimentalbiomedicalresearch.com

$\triangle$ Mustafa Ayhan Ekici, Department of Gynecology and Obstetrics, Bolu Abant Izzet Baysal University, Faculty of Medicine, Bolu, Turkey.

E-mail: mayhanekici@hotmail.com
Received: 2019-12-04 / Accepted: 2019-12-24

Publication Date: 2020-01-01 


\section{Introduction}

Pelvic organ prolapse (POP) is a common health problem which has significant negative effects on women's life quality. POP is seen in approximately $30-40 \%$ of women who had given birth. The lifetime risk of surgery for POP in the general female population is approximately 19\% [1]. Vaginal hysterectomy $(\mathrm{VH})$ is the most common procedure for the surgical treatment of uterovaginal prolapse (UVP) [2,3]. Gynecologists usually encounter POP during uterine conservation surgery [4]. However, many surgeons are unwilling to preserve the uterus during POP surgery, since there may be lesions that develop later and require uterine evaluation and /or hysterectomy.

In the literature, risk of unsuspected gynecological malignancy after hysterectomy for POP ranges between 0.0 and $0.9 \%$ [5,6]. Hence, this study aimed to investigate the incidence of malignant and/or premalignant pathological results of women with normal cervical cytology and transvaginal ultrasound who underwent hysterectomy for POP.

\section{Materials and Methods}

This retrospective cohort was conducted after getting approval from the ethics committee of Abant İzzet Baysal University (Decision no: 2019/325). All patients were selected from İzzet Baysal State Hospital and Abant İzzet Baysal University Hospital, who underwent hysterectomy for POP between Jan. 1, 2007 and November. 14, 2019. Patients were evaluated according to International Classification of Diseases, Revision Ten codes. Data were collected from a retrospectively maintained departmental billing database. The database access granted from International Classification of Disease codes, current procedural terminology. Medical records of the patients including clinical characteristics and past medical histories were collected from the hospital database. Pathology reports were reviewed for the final pathology.

Patients who underwent hysterectomy according to International Classification of Disease Revision Ten codes (ICD 10) N 81.4 (Uterovaginal prolapse, unspecified), N 81 (Female genital prolapse), N81.2 (Incomplete uterovaginal prolapse), N81.3 (Complete uterovaginal prolapse), N81.8 other (Female genital prolapse) and N81.9 (Female genital prolapse, unspecified) diagnoses were included in this study. In addition, patients enrolled to this study had a normal cervicovaginal smear test in the last one year or a negative cervicovaginal cytology test and human papilloma virus within three years before surgery. Women without abnormal uterine bleeding symptoms or abnormal endometrial findings do not routinely undergo endometrial biopsies in daily surgical practice. Patients with premalignant and / or malignant adnexal, uterine or cervical pathology were excluded from the study. Women whose last menstruation was retarded more than 1 year, who were postmenopausal and over 40 years old were also discarded. Menorrhagia, intermenstrual bleeding and postmenopausal bleeding were considered as abnormal uterine bleedings. Treatment approaches in this study were recorded as laparoscopic hysterectomy, vaginal hysterectomy, and abdominal hysterectomy.

\section{Statistical analysis}

Data analysis was performed using SPSS version 23.0 (SPSS Inc. USA). Student $t$-test was used to evaluate the possible relationship between pathologic results and other variables. Chi-square test was used to evaluate abnormal pathologic results between each hysterectomy type. The results were assessed within 95\% 
confidence interval. A $\mathrm{p}$ value $<0.05$ was considered as statistically significant.

\section{Results}

Five hundred and twenty four hysterectomies with the indication of POP were performed during the study period, including abdominal $(160,30.53 \%)$, laparoscopic $(62,11.83 \%)$ and vaginal approaches $(302,57.63 \%)$ (Table 1). The mean age of the women in this study was $51.34 \pm 9.62$ years $(50.5-52.2,95 \% \mathrm{CI})$. Table 2 shows preoperative diagnosis of patients.

Table 1. Surgical procedures for pelvic organ prolapse (POP) treatment.

\begin{tabular}{|l|c|}
\hline Procedure & n (\%) \\
\hline Hysterectomy, all & $524(100)$ \\
\hline Vaginal & $302(57.7)$ \\
\hline Abdominal & $160(30.5)$ \\
\hline Laparoscopic & $62(11.8)$ \\
\hline Oophorectomy & $253(48.3)$ \\
\hline Incontinence procedure & $196(37.4)$ \\
\hline Transobturator tape (TOT) technique & $157(29.9)$ \\
\hline $\begin{array}{l}\text { Marshall-Marchetti-Krantz procedure } \\
\text { MMK) }\end{array}$ & $39(7.4)$ \\
\hline Colporrhaphy & $421(80.3)$ \\
\hline Anterior & $155(29.6)$ \\
\hline Posterior & $53(10.1)$ \\
\hline Anterior and posterior & $209(39.9)$ \\
\hline
\end{tabular}

Primary indications for hysterectomy were (N 81.4) Uterovaginal prolapse, unspecified (275, 52.48\%), (N 81) Female genital prolapse (101, 19.27\%), (N81.2) Incomplete uterovaginal prolapse (61, 11.64\%), (N81.3) Complete uterovaginal prolapse $(51,9.73 \%)$, (N81.8) other Female genital prolapse $(24,4.58 \%)$ and (N81.9) Female genital prolapse unspecified $(12,2.29 \%)$. In preoperative screening,
Table 2. Distribution of preoperative diagnosis.

\begin{tabular}{|l|c|}
\hline Preoperative diagnosis (ICD 10) & $\mathbf{n}(\%)$ \\
\hline Female genital prolapse(N 81) & $101(19.27)$ \\
\hline Incomplete uterovaginal prolapse(N 81.2) & $61(11.4)$ \\
\hline Complete uterovaginal prolapse (N 81.3) & $51(9.73)$ \\
\hline Uterovaginal prolapse, unspecified(N 81.4) & $275(52.48)$ \\
\hline Other female genital prolapse (N 81.8) & $24(4.58)$ \\
\hline Female genital prolapse, unspecified (N81.9) & $12(2.29)$ \\
\hline Abnormal uterin bleeding (N 92) & $18(3.44)$ \\
\hline Leiomyoma uteri (D 25) & $160(30.53)$ \\
\hline Stres urinary incontinence( N39.3) & $196(37.4)$ \\
\hline
\end{tabular}

eighteen patients (3.44\%) were detected to have abnormal uterine bleeding symptoms. None of them was postmenopausal.

Preoperative diagnostic evaluation with ultrasound scanning and/or endometrial biopsy was negative for malignant and premalignant disease. Women with no symptoms or abnormal gynecological examination do not routinely undergo endometrial sampling in daily surgical practice.

Table 3 shows pathological results after hysterectomy of the study subjects. Thirty five patients (6.67\%; 95\% CI, 5.7-7.2) have unsuspected premalignant or malignant gynecological pathological result found after hysterectomy. Simple hyperplasia without atypia were detected in 18 patients $(3.44 \%$; 95\% CI, 2.34-4.56), complex hyperplasia without atypia in two patients $(0.38 \% ; 95 \% \mathrm{CI}$, 0.21-1.49), CIN-I (cervical intraepithelial neoplasia) in nine patients $(1.7 \%$; $95 \mathrm{CI}, 1.5$ $1.9), \mathrm{CIN}-\mathrm{II}$ in two patients $(0.38 \%$; $95 \% \mathrm{CI}$, 0.21-1.49), one CIN-III in one patient $(0.19 \%$; 95\% CI, 0.11-0.27), vaginal carcinoma in two patients $(0.38 \% \quad ; 95 \%, 0.21-1.49)$ and endometrial carcinoma in one patient $0.19 \%$; 95\% CI, 0.11-0.27) after pathology reporting. 
Table 3. The pathology results after the hysterectomy.

\begin{tabular}{|l|l|l|}
\hline Specimen & $\mathbf{n}(\%)$ & $\mathbf{9 5} \% \mathbf{C I}$ \\
\hline Uterus (n=524) & & \\
Leiomyoma(s) & $213(40.6)$ & $36.8-44.5$ \\
Adenomyosis & $126(24.1)$ & $21.2-27.2$ \\
Endometrial polyp & $45(8.6)$ & $6.5-10.7$ \\
\cline { 2 - 3 } Endometrial hyperplasia & & \\
Simple & $18(3.44)$ & $2.34-4.56$ \\
Complex & $2(0.38)$ & $0.21-0.49$ \\
Endometrial carcinoma & $1(0.19)$ & $0.11-0.27$ \\
\hline Cervix (n=524) & & \\
CIN1 & $9(1.7)$ & $1.5-1.9$ \\
CIN2 & $2(0.38)$ & $0.32-0.41$ \\
CIN3 & $1(0.19)$ & $0.11-0.27$ \\
\hline Vaginal cancer & $2(0.38)$ & $0.32-0.41$ \\
\hline
\end{tabular}

These unexpected premalign gynecological pathologies $(6.09 \%)$ were detected in premenopausal women. In total, women diagnosed with unexpected gynecological malignancies after a hysterectomy was three $(0.57 \%)$. These included two vaginal squamous cell carcinomas $(0.38 \%)$ and one endometrioid type of endometrium adenocarcinoma $(0.19 \%)$.
Comparison of the numbers of Unexpected Uterine Malignancy (UUM) among abdominal, laparoscopic and vaginal hysterectomy are shown in table 4. Statistically significant difference was not found with respect to mean age of abdominal hysterectomy, laparoscopic and vaginal hysterectomy groups $(51.75 \pm 9.83$, $51.32 \pm 9.51$ and $51.39 \pm 10.04$, respectively, $p=0.299$ ).

No significant difference was observed with respect to the incidence of patients diagnosed with UUM after hysterectomy in laparotomic, laparoscopic and vaginal hysterectomy groups (laparotomy, 0 [0.0\%]; laparoscopy, 0 [0.0\%]; vaginal, $1[0.19 \%] p=0.077)$. The incidence of unsuspected gynecological malignancy after hysterectomy was $0.57 \%$ (3/ 524) which was significantly higher in vaginal hysterectomy group $(p=0.01)$. The incidences of UUM, unsuspected endometrial malignancy and unexpected gynecological malignancy other than endometrial malignancy were $0.19 \%$ (1/524 patients), $0.19 \%$ (1/524 patients) and $0.38 \%$ (2/524 patients), respectively.

In the cohort of women found to have an unanticipated uterine malignancy after hysterectomy, the median age at the time of diagnosis was 58 years (range 51-65). The age of unsuspected endometrial malignancy case

Table 4. The distribution of unexpected gynecological malignancies after the hysterectomy.

\begin{tabular}{|l|l|l|l|l|l|}
\hline Gynecological malignancies & TAH & TLH & VH & Total & $P^{\mathbf{a}}$ \\
\hline Mean age (Years) & $51.7 \pm 9.8$ & $51.3 \pm 9.5$ & $51.3 \pm 10$ & $51.3 \pm 9.6$ & 0.299 \\
\hline Leiomyosarcoma & $0(0.0)$ & $0(0.0)$ & $0(0.0)$ & $0(0.0)$ & \\
\hline Endometrioid carcinoma & $0(0.0)$ & $0(0.0)$ & $1(0.19)$ & $1(0.19)$ & 0.077 \\
\hline $\begin{array}{l}\text { Squamous-cell carcinoma of } \\
\text { the vagina }\end{array}$ & $0(0.0)$ & $0(0.0)$ & $2(0.38)$ & $2(0.38)$ & 0.043 \\
\hline Total & $0(0.0)$ & $0(0.0)$ & $3(0.57)$ & $3(0.57)$ & 0.01 \\
\hline
\end{tabular}

Data are expressed as $\mathrm{n}(\%)$ and $\mathrm{Maen} \pm \mathrm{SD}$. ${ }^{\mathrm{a}} \mathrm{Chi}$-Square test. TAH: total abdominal hysterectomy, TLH: total laparoscopic hysterectomy, VH: vaginal hysterectomy. 
was 51 years, her preoperative endometrial thickness was $15 \mathrm{~mm}$, and preoperative endometrial sampling pathologic result was proliferative endometrium and postoperative hysterectomy pathologic result was stage 0 endometrioid type adenocarcinoma grade I. This patient did not receive any additional surgery or treatments at the time of observation. Vaginal squamous cell carcinoma cases were determined to vaginal pathologic specimen who underwent vaginal hysterectomy. One of these cases was 58 and the other was 66 years old. In these two patients, vaginal prolapse was present for more than 10 years and they underwent vaginal hysterectomy with a diagnosis of stage 4 uterovaginal prolapse. The result of postoperative pathology in which tissues were extracted from the posterior vaginal walls revealed Stage 2A squamous cell carcinoma well differentiated type. These patients received radiotherapy after diagnosis. No surgical treatment was performed again.

\section{Discussion}

The results of uterine protective surgery for POP treatment showed very low risk of unexpected premalignant or malignant gynecologic disease $(6.67 \%)$. The unsuspected malignancy risk was $0 \%$ among premenopausal women in our patient group. Though, $6.09 \%$ of premenopausal women were diagnosed with endometrial hyperplasia or cervical intraepithelial neoplasia after hysterectomy and reconstructive surgery, only $0.57 \%$ of the patients had detected gynecological malignancy. The unexpected uterine malignancy risk was $0.19 \%$ and unexpected gynecological malignancy other than uterine malignancy risk was $0.38 \%$ in our study.

Patients without abnormal uterine bleeding symptoms had minimal risk of unsuspected disease. On the other hand, postmenopausal women suspected of bleeding patterns have significant risk for unsuspected malign disease and are not good candidates for uterine conservation [5]. But, postmenopausal patients without abnormal uterine or vaginal bleeding have a low risk of abnormal pathology $(0.57 \%)$. Incidence rates were reported to be $0-0.9 \%$ in previous studies (Table 5). Frick et al. [6] reviewed 644 hysterectomy cases with POP and found two unsuspected malignancies $(0.3 \%)$. They found cancer cases in patients with postmenopausal bleeding. Ram et al. found that very few women undergoing POP surgery had undiagnosed serious endometrial pathologic results $(0.7 \%)$, with five of them incidentally diagnosed with uterine cancers (0.6\%) [7]. These cancer cases were detected in postmenopausal patients with abnormal endometrial thickness without abnormal uterine bleeding. Similar to this study, we also detected unexpected endometrial cancer cases were detected in postmenopausal patients with higher endometrial thickness and without postmenopausal hemorrhage. In the present study, the rate of unexpected endometrial malignancy was $0.19 \%$ and vaginal squamous cell carcinoma was $0.38 \%$ in patients who underwent vaginal hysterectomy with the diagnosis of UVP. Similarly; unexpected endometrial malignancy incidence has been reported between 0-0.54 percent in hysterectomies performed with the diagnosis of pelvic floor dysfunction [8-10]. Previous studies did not report unexpected cases of vaginal cancer. It may be because the vaginal tissue was not removed or the extracted vaginal tissues were not taken into pathological examination.

Our results show that abnormal gynecological pathology risk is low after hysterectomy and does not show the risk of uterine, adnexal, vaginal or cervical disease for the rest of 
Table 5. Incidence of premalignant and malignant uterine findings after hysterectomy for pelvic organ prolapse - summary of previous studies.

\begin{tabular}{|l|l|l|l|l|}
\hline Study & $\mathbf{n}$ & $\begin{array}{l}\text { Significant a } \\
\text { premalignant } \\
\text { uterine findings }\end{array}$ & $\begin{array}{l}\text { Unexpected } \\
\text { uterine } \\
\text { malignancy }\end{array}$ & Total \\
\hline Frick et al. [6] (2010) & 644 & $7(1.08 \%)$ & $2(0.3 \%)$ & $9(1.39 \%)$ \\
\hline Ramm et al. [7] (2012) & 708 & $2(0.28 \%)$ & $5(0.7 \%)$ & $7(0.98 \%)$ \\
\hline Wan et al. [8] (2013) & 640 & $2(0.31 \%)$ & $2(0.31 \%)$ & $4(0.62 \%)$ \\
\hline Andy et al. [9] (2014) & 324 & $3(0.92 \%)$ & 0 & $3(0.92 \%)$ \\
\hline Ackenbom et al. [10] (2016) & 1196 & $10(0.8 \%)$ & $3(0.3 \%)$ & $3(1.1 \%)$ \\
\hline Grigoriadis et al. [11] (2015) & 333 & $13(3.9 \%)$ & $1(0.3 \%)$ & $14(4.2 \%)$ \\
\hline Mizrachi et al. [12] (2017) & 677 & $5(0.73 \%)$ & $1(0.15 \%)$ & $6(0.88 \%)$ \\
\hline Present study & 524 & $5(0.95 \%)$ & $1(0.19 \%)$ & $6(1.14 \%)$ \\
\hline
\end{tabular}

" Significant premalignant pathological findings were defined as either atypical endometrial hyperplasia or cervical intraepithelial neoplasia grade $2-3$ b cervical cancer.

patient's life. Surgical procedure should not include removing of the ovarian tissue. So, incidentally abnormal ovarian pathology is expected to occur only in a few patients, even a little normal appearance of the ovaries is seen intraoperative.

Our study had some limitations. First, this is a retrospective study. Second, this study does not provide information about ovarian pathologies, third, preoperative examinations are not performed in the same clinic and there may be inadequate or incomplete evaluations resulting from this.

The strengths of our study are that the number of patients is high and that the patients with postmenopausal bleeding are not included.

\section{Conclusion}

The rate of incidentally found premalignant or malignant gynecological pathological findings in patients who underwent hysterectomy with the diagnoses of POP were not frequent
$(0,57 \%)$ in this study, but the risk should not be ignored. Therefore, patients who underwent surgery due to POP must be informed about the risk of unexpected gynecological malignancy.

Funding: There is no financial support and sponsorship

Conflict of Interest: The authors declare that they have no conflict of interest.

\section{ORCID iD of the author(s)}

Mustafa Ayhan Ekici / 0000-0002-0745-0907

Ali Can Onal / 0000-0001-6078-7325

\section{References}

[1]Swift SE. The distribution of pelvik organ support in a population of female subjects seen for routine gynecologic healthcare. Am J Obstet Gynecol. 2000;183(2):277-85.

[2]Johnson N, Barlow D, Lethaby A, et al. Surgical approach to hysterectomy for 
benign gynaecological disease. Cochrane Database Syst Rev. 2005;(1):CD003677.

[3]Renganathan A, Edwards R, Duckett JR. Uterus conserving prolapse surgery-what is the chance of missing a malignancy? Int Urogynecol J. 2010;21(7):819-21.

[4]Schulten SFM, Detollenaere RJ, Stekelenburg J, et al. Sacrospinous hysteropexy versus vaginal hysterectomy with uterosacral ligament suspension in women with uterine prolapse stage 2 or higher: observational follow-up of a multicentre randomised trial. BMJ. 2019; 366:15149.

[5]vanHanegem N, Prins MMC, Bongers MY, et al. The accuracy of endometrial sampling in women with postmenapozal bleeding: asystematic review and meta-analysis. Eur J Obstet Gynecol Reprod Biol. 2016;197:14755 .

[6]Frick AC, Walters MD, Larkin KS, et al. Risk of unanticipated abnormal gynecologic pathology at the time of hysterectomy for uterovaginal prolapse. Am J Obstet Gynecol. 2010;202(5):507.e1-507.e5074.

[7]Ramm O, Gleason JL, Segal S, et al. Utility of preoperative endometrial assessment in asymptomatic women undergoing hysterectomy for pelvic floor dysfunction. Int Urogynecol J. 2012;23(7):913-17.

[8]Wan OY, Cheung RY, Chan SS, et al. Risk of malignancy in women who underwent hysterectomy for uterine prolapse. Aust N Z J Obstet Gynaecol. 2013; 53(2):190-96.

[9]Andy UU, Nosti PA, Kane S, et al. Incidence of unanticipated uterine pathology at the time of minimally invasive abdominal sacrocolpopexy. J Minim Invasive Gynecol. 2014;21(1):97-100.

[10] Ackenbom MF, Giugale LE, Wang Y, et al. Incidence of occult uterine pathology in women undergoing hysterectomy with pelvic organ prolapse repair. Female Pelvic Med Reconstr Surg. 2016;22(5):332-35.

[11] Grigoriadis T, Valla A, Zacharakis D, et al. Vaginal hysterectomy for uterovaginal prolapse: what is the incidence of concurrent gynecological malignancy? Int Urogynecol J. 2015;26(3):421-25.

[12] Mizrachi Y, Tannus S, Bar J, et al. Unexpected significant uterine pathological findings at vaginal hysterectomy despite unremarkable preoperative workup. Isr Med Assoc J. 2017;19(10):631-34. 